\title{
新製品・新技術
}

\section{スーパーファインサーメットGT/NS700 シリーズの開発}

小池 広樹, 梅村 崇, 船水 健司, 木下 聡

侏タンガロイ，９ 970-1144 いわき市好間工業団地 11-1.

\section{Development of Super Fine Cermet GT/NS700 Series}

\author{
Hiroki Koike, Takashi Umemura, Kenji Funamizu and Satoshi Kinoshita \\ Tungaloy Corp., 11-1 Yoshima Industrial Estate, Iwaki 970-1144, Japan.
}

Received November 1, 2007

\begin{abstract}
SYNOPSIS
It is increasing in the importance of the highly efficient processing of high speed or high feed rate cutting as the means of the cost reduction and the environmental protection. $\mathrm{Ti}(\mathrm{C}, \mathrm{N})$ based cermet indicates high wear resistance as low reactivity with steel. High efficiency cutting of $\mathrm{Ti}(\mathrm{C}, \mathrm{N})$ based cermet is important to improved plastic deformation at high temperature. It's indicated microstructure of $\mathrm{Ti}(\mathrm{C}, \mathrm{N})$ based cermet depend on grain size of powder, plastic deformation resistance of $\mathrm{Ti}(\mathrm{C}, \mathrm{N})$ based cermet increasing with increase amount of WC in a series of studies. Super fine cermet GT/NS700 series is developed based this research for long tool life and stable high speeds cutting.
\end{abstract}

\section{KEY WORDS}

cermet, $\mathrm{Ti}(\mathrm{C}, \mathrm{N})$ powder particle size, WC addition, toughness

\section{1 開発の背景, 目的}

加工精度向上の要求に加え, コスト低減および環境対策の ため高能率加工の要求が高まっている. Ti(C,N)基サーメット にとっての高能率加工とは, 高速度, 高切込み, 高送りといっ た適用領域を拡大することであり, 高温時の耐塑性変形性を 改善することが重要と考えられた。スーパーファインサー メットGT/NS700 シリーズは, 高温時の耐塑性変形性を改善 したインサート用のサーメット材料であり, 長寿命, 安定加 工により高能率加工を実現することが出来た.

\section{2 技術内容, 特徴}

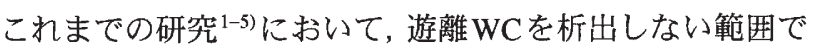
$\mathrm{WC}$ 量 $\left(F_{\mathrm{WC}}\right)$ を増加させることにより硬質かつクリープ変形し にくいサーメットが得られることが分かった. スーパーファ インサーメットGT/NS700シリーズ開発の基盤技術となった, 研究成果について以下に紹介する.

はじめに Ti(C,N)-WC-NbC-Ni サーメットの合金組織およ び機械的特性に及ぼす $\mathrm{Ti}(\mathrm{C}, \mathrm{N})$ 粒子径および WC 添加量の影 響を調べた. Fig.1は， $F_{\mathrm{wC}}$ および湿式ボールミル時間 $\left(t_{m}\right)$ を 変化させた試料の内部組織を示す。これらの合金組織は, 次 に記す 4 つの特徵を有する. (1) $t_{m}$ が大であるほど, 硬質相粒 子が微細であった。(2) Ti(C,N) 粒子が微細であるほど, 有芯
構造を示さない $\mathrm{Ti}(\mathrm{C}, \mathrm{N})$ の単独粒子は滅少し, Ti(C,N)をコア とする有芯構造粒子(黒色コア粒子)および $(\mathrm{Ti}, \mathrm{W}, \mathrm{Nb})(\mathrm{C}, \mathrm{N})$ を コアとする有芯構造粒子 (淡灰色コア粒子) が増加した. (3) $F_{\mathrm{WC}}$ の増加とともにTi $(\mathrm{C}, \mathrm{N})$ 単独粒子および淡灰色コア粒子が 増加し, 黒色コア粒子は減少すると共にスケルトン構造が増 大した. (4) $t_{m}=54 \mathrm{ks}$ かつ $F_{\mathrm{WC}}=14 \%$ のみ白色の遊離 WC が観 察された。これは $F_{\mathrm{WC}}$ が大であるため, 焼結過程において Ni 融液中の $\mathrm{W}$ 量法常に多量であり, $\mathrm{Ni}$ 融液中の $\mathrm{W}$ は淡灰色リ ムおよび濃灰色リムとして全て析出することができず, 焼結 後, 遊離 WCとして析出したと考えられる.

次に,これらの合金について機械的特性を調べた. Fig.2に ビッカース硬度 $\left(H_{\mathrm{V}}\right)$ と平均自由行路 $\left(l_{\mathrm{Ni}}\right)$ および $\mathrm{Ti}(\mathrm{C}, \mathrm{N})$ 平均 粒度 $\left(d_{\mathrm{CN}}\right)$ の関係を示す. 同一 $l_{\mathrm{Ni}}$ においても $F_{\mathrm{WC}}$ が増加するほ ごH は大となる結果が得られた.これは黒色コア粒子のリム および淡灰色コア粒子のコアおよびリムへのW固溶量が増加 することによると考えられる，高温クリープ試験 $(1373 \mathrm{~K}$ ， $\sigma=0.3 \mathrm{GPa})$ を行い, Fig.3に定常クリープ変形速度 $(\dot{\varepsilon})$ と $F_{\mathrm{WC}}$ および $t_{\mathrm{m}}$ の関係を示す. $\dot{\varepsilon}$ は $t_{\mathrm{m}}$ にほとんど依存せず, $F_{\mathrm{wc}}$ の増 加とともに著しく小となった。つまり $F_{\mathrm{wC}}$ の増加によりク リープ変形しにくくなった. Fig. 4 に $F_{\mathrm{WC}}=0,6,10 \%, t_{\mathrm{m}}=54 \mathrm{ks}$ 合金を用い，三点曲げクリープ試験を行い，一定クリープ歪 量 $(\varepsilon=0.6 \%)$ を与えた張力面の SEM 組織写真を示す. 一定 $\varepsilon$ 


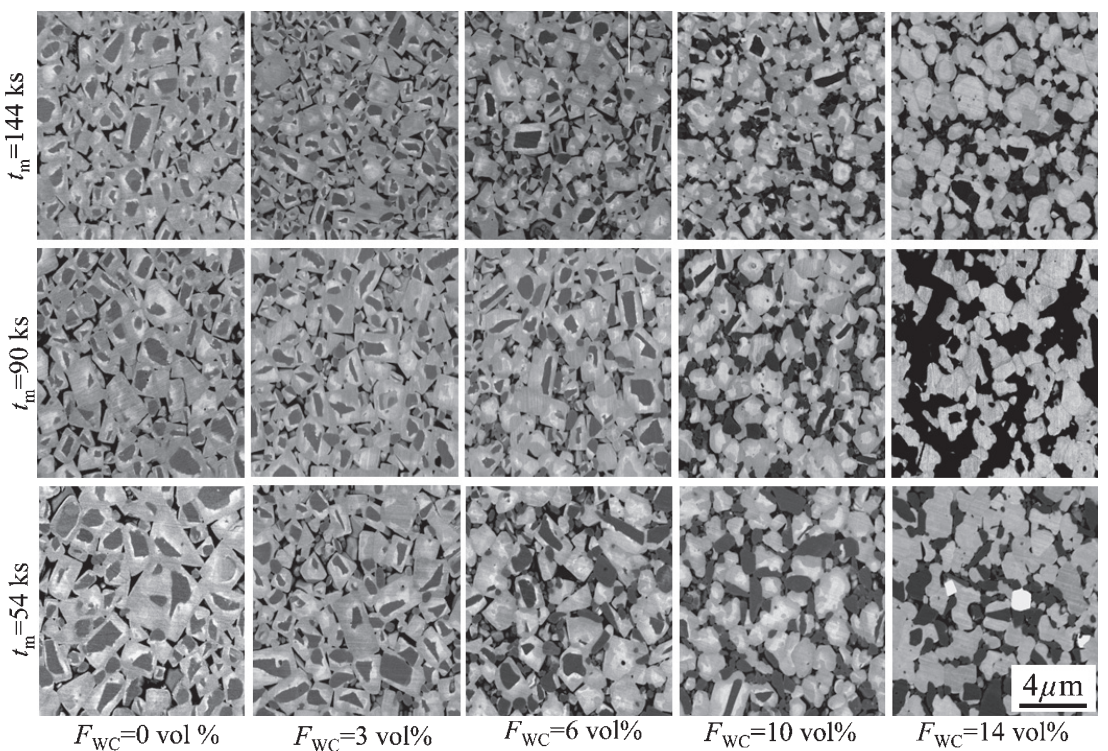

Fig.1 Effects of $F_{\mathrm{WC}}$ and $t_{\mathrm{m}}$ on SEM microstructures of $\mathrm{Ti}\left(\mathrm{C}_{0.5} \mathrm{~N}_{0.5}\right)-\mathrm{WC}-6 \mathrm{vol} \% \mathrm{NbC}-10 \mathrm{vol} \% \mathrm{Ni}$ cermet, Sintered at $1803 \mathrm{~K}$ for $3.6 \mathrm{ks}$. Etched in aqua regalis.

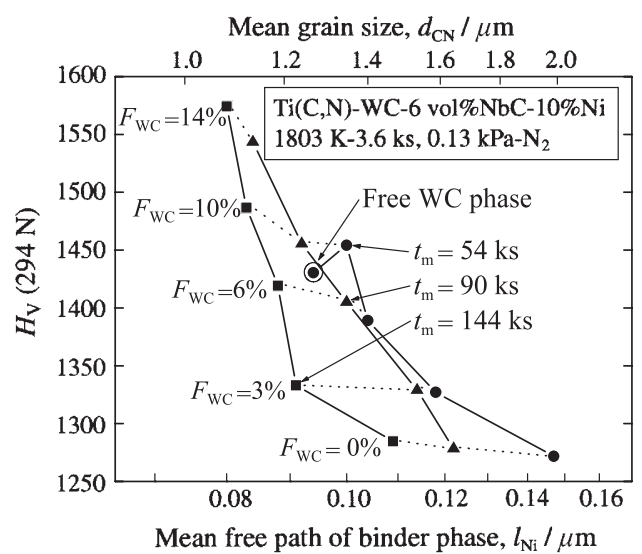

Fig.2 Effect of $F_{\mathrm{Wc}}$ and $t_{\mathrm{m}}$ on $H_{\mathrm{V}}(294 \mathrm{~N})$.

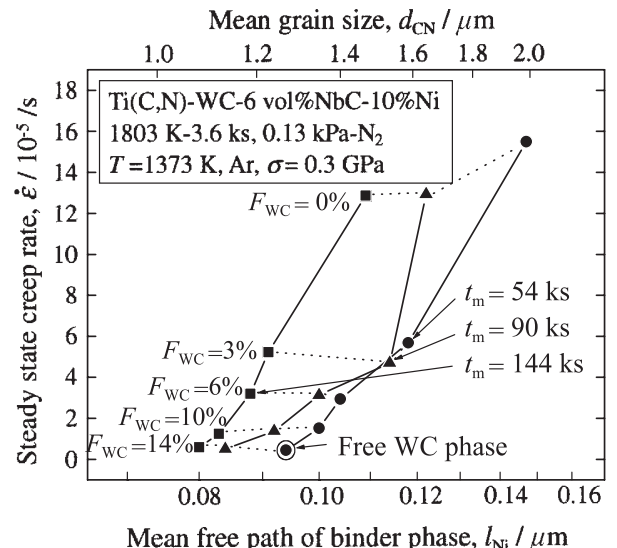

Fig.3 Effect of $F_{\mathrm{WC}}$ and $t_{\mathrm{m}}$ on steady state creep rate. FWC and tm on steady creep rate.

での張力面に生じるクラックの数および幅は $F_{\mathrm{wC}}$ の増加とと もに減少した。このことから $F_{\mathrm{WC}}$ の増加にともなう $\dot{\varepsilon}$ の減少

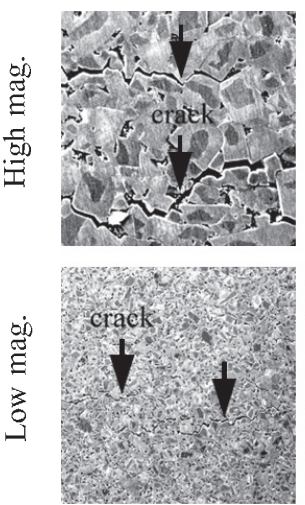

$F_{\mathrm{WC}}=0 \mathrm{vol} \%$
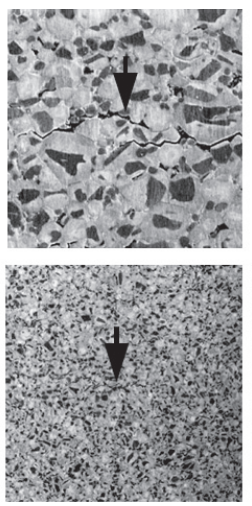

$F_{\mathrm{WC}}=6 \mathrm{vol} \%$

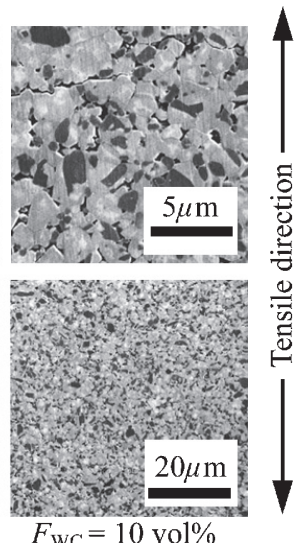

$F_{\mathrm{WC}}=10 \mathrm{vol} \%$
Fig.4 Effect of $F_{\mathrm{wC}}(0 \%, 6 \%$ and $10 \%)$ on SEM microstructures of tensile side surface as creep-rupture strength test.

は, $F_{\mathrm{WC}}$ の増加にともなうスケルトン構造の増加およびスケ ルトン強度の増大によるものと考えられた。

上記技術により開発した新サーメットNS730について, Fig.5には切削油を用いた間欠切削時の耐欠損性試験結果を, Fig.6には300サイクル時の工具表面損傷写真を示す.これら の結果より NS730 は他社品と比較して 1.5 倍の切削サイクル を加工しても欠損しない結果が得られた．また，チップ刃先 部を見るとNS730はクラックの発生が見られず，熱サイクル によるクラックの発生/進展を抑えることで耐欠損性が向上 したことが分かる.

Fig.7に機械的衝撃サイクルによる耐欠損試験方法を, Fig.8 にその結果を示す。NS730および PVD 被覆した GT730 とも に他社品と比較して約 2.5 倍の衝撃回数に耐えられる結果が 得られた。

以上のように WC 添加量の最適化，および $0.7 \mu \mathrm{m}$ の微粒, 


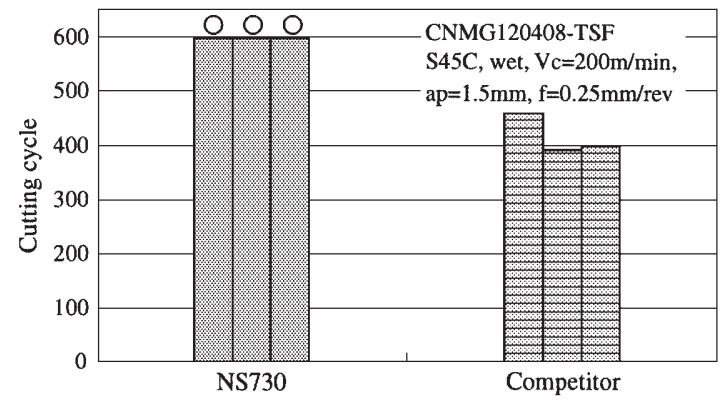

Fig.5 Result of thermal shock resistance test.

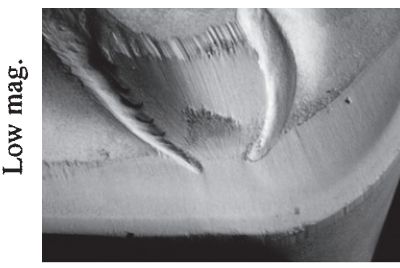

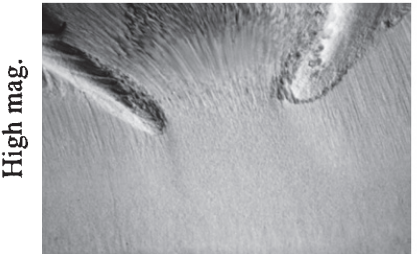

NS730
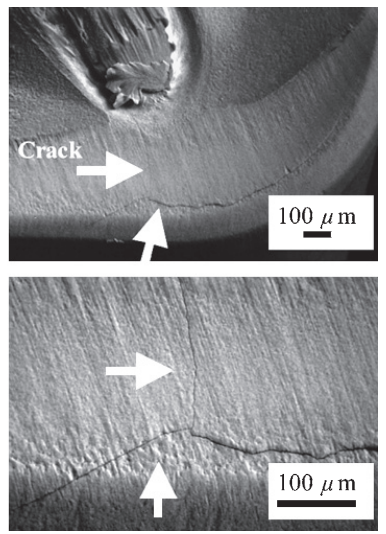

Competitor

Fig.6 Thermal cracks on insert surface as thermal shock resistance test.

$\operatorname{Ti}(\mathrm{C}, \mathrm{N})$ を採用したことにより,開発目標であった耐摩耗性と 耐欠損性の両立を達成することが可能となった。

\section{3 用途, 適用範囲}

スーパーファインサーメットGT/NS700シリーズは, 旋削 用の新サーメットシリーズで, 3 つの材種より構成されてい る. 広い速度領域をカバーした汎用性の高いGT730, 高速仕 上げ加工で耐摩耗性に優れる GT720, 耐欠損性を重視した NS730を設定した.

\section{4 今後の展開}

経済産業省は平成 19 年度より希少金属代替材料開発プロ ジェクトを発足させ, 超硬工具向けタングステンを現状から 30\%削減する方針を出した. 超硬工具を代替する材料として サーメットが有力候補であるが, 耐欠損性の改善を必要とす るため, $\mathrm{Ti}(\mathrm{C}, \mathrm{N})$ 基をべースにしたサーメットに加え, 他の炭 窒化物基の研究・開発が活発化すると予想される.

\section{特 許}

（1）特開2005-350707 サーメットおよび被覆サーメット並びに それらの製造方法

(2) 特開2005-200668 サーメットおよび被覆サーメット並びに それらの製造方法

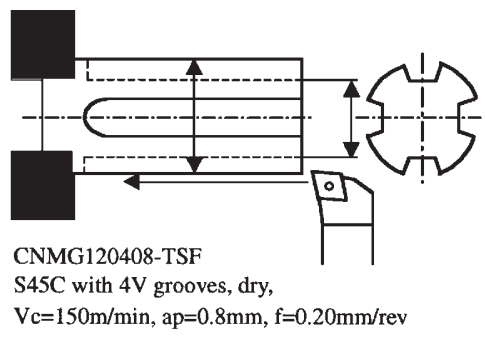

Fig.7 Cutting condition of fracture resistance test.

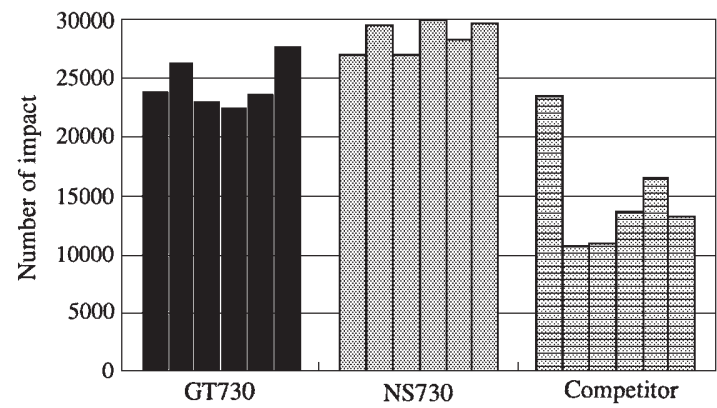

Fig. 8 Result of fracture resistance test. GT730 is a coated cermet.

(3) 特開2005-194573 サーメットおよび被覆サーメット並びに それらの製造方法

(4) 特開 2004-292842 サーメット

(5) 特開 2004-285421 サーメット

\section{文献}

1) T.Umemura, N.Hojo, S.Kinoshita, Y.Taniguchi and K.Hayashi: "Effect of WC Content and Ti(C,N) Powder Particle Size on Microstructure of Ti(C,N)-WC-NbC-Ni Cermet", Abstracts of Spring Meeting of Japan Society of Powder and Powder Metallurgy, (2003)33.

2) K.Funamizu, T.Umemura, S.Kinoshita, Y.Taniguchi and K.Hayashi: "Effect of WC Content and Ti(C,N) Powder Particle Size on Mechanical Properties of Ti (C,N)-WC-NbC-Ni Cermet", Abstracts of Autumn Meeting of Japan Society of Powder and Powder Metallurgy, (2003)170.

3) K.Funamizu, T.Umemura, S.Kinoshita, Y.Taniguchi and K.Hayashi: "Studies on Microstructure of $\mathrm{Ti}(\mathrm{C}, \mathrm{N})-\mathrm{WC}-\mathrm{NbC}-$ Ni Cermet", Abstracts of Spring Meeting of Japan Society of Powder and Powder Metallurgy, (2004)141.

4) K.Funamizu, T.Umemura, S.Kinoshita, Y.Taniguchi and K.Hayashi: "Effect of Microstructure on Mechanical Properties of $\mathrm{Ti}(\mathrm{C}, \mathrm{N})-\mathrm{WC}-\mathrm{NbC}-\mathrm{Ni}$ Cermet", Abstracts of Autumn Meeting of Japan Society of Powder and Powder Metallurgy, (2004)58.

5) K.Funamizu, T.Umemura, S.Kinoshita, Y.Taniguchi and K.Hayashi: "Effect of Microstructure on Cutting Performance of Ti(C,N)-WC-NbC-Ni Cermets", Abstracts of Spring Meeting of Japan Society of Powder and Powder Metallurgy, (2005)143. 